\title{
AC 2008-1890: NEGOTIATING THE PATH TO THE PROFESSORIATE: A STUDY OF FACULTY PERSPECTIVES IN MECHANICAL ENGINEERING
}

Monica Young, Syracuse University

John Tillotson, SYRACUSE UNIVERSITY 


\title{
Negotiating the Path to the Professoriate: A Study of Faculty Perspectives in Mechanical Engineering
}

\begin{abstract}
$\underline{\text { Abstract }}$
This qualitative study investigated the factors that support or impede women's interest and persistence in the field of mechanical engineering and how these experiences influence their decision to complete a doctoral program and advance on to a career in academia. This study examined key variables along the STEM continuum that contribute to the gender gap among engineering faculty members through comparative case studies of female and male mechanical engineering professors from eight universities across the United States. This study also compared the perceptions of male and female engineering professors concerning the departmental and institutional climate within their respective university engineering programs. The intent was to determine the commonalities and differences that exist within and between these two groups to gain additional insight into the problem of underrepresentation of women in STEM fields. The data suggest that male and female faculty members agree that early and sustained mentoring is key in recruiting and retaining female students in engineering. They also assent that the tenure process is essentially the same for all faculty members, but many male faculty members neglected to consider the unique challenges associated with childbirth and extension of the tenure clock that many women face. Female faculty members expressed greater difficulty establishing research collaborations, but all faculty members realized the potential for a more positive departmental climate as more female faculty members are hired.
\end{abstract}

\section{$\underline{\text { Introduction }}$}

The global economy in the $21^{\text {st }}$ century requires the United States to invest significantly in science, technology, engineering, and mathematics (STEM) education to ensure our prominence and leadership in the advancement of scientific and technological knowledge. For decades, excellence in building and sustaining institutions of higher education that attract science and engineering talent from all over the world has defined this nation. When it comes to supporting the limitless potential of women, underrepresented minorities, and persons with disabilities in STEM research and education, however, the United States has fallen short - even while developing this potential would significantly expand our overall national competitiveness and prosperity ${ }^{\$}$.

Engineering as a field has suffered most seriously from the shortage of women entering and advancing through the STEM education pipeline. The National Science Board in its Science and Engineering Indicators 2006 report found that, although the number of women earning doctoral degrees in engineering fields increased between 1991-2003, women still lag far behind men, comprising just $17 \%$ of the total doctoral degrees awarded ${ }^{2}$. At earlier levels of education, these numbers are comparable. The attrition of women as compared to men on the path to the Ph.D. results in the ever-widening gap in numbers of women achieving advanced academic positions in STEM disciplines causing an overall ripple effect on future generations ${ }^{3}$.

It is imperative that researchers inquire into what contributes to the under-representation of women in STEM - specifically, those factors that encourage or discourage interest and persistence in pursuing advanced degrees and careers in science and particularly in engineering ${ }^{4}$. Some researchers argue that without women in visible leadership roles in engineering academia there is no incentive for young women to enter the field ${ }^{5,6}$. Others believe that the climate within institutions and engineering departments strongly impedes the success of female faculty members and students $7,8,9,18$. Many contend that mentoring plays a critical role in all stages of academia and the lack of female mentors or role models results in a smaller number of women entering graduate school ${ }^{5,11,12,13,14}$. If STEM professionals are to be successful in creating more 
effective recruiting programs in K-12 and retain talented females in the academic pipeline, then researchers must carefully examine how current female engineering faculty members have successfully negotiated the path to the professoriate.

\section{Statement of the Problem}

In the two largest fields of engineering, mechanical and electrical/computer, the percentage of female tenured or tenure-track faculty members are 9.8 and 8.5 percent, respectively ${ }^{20}$. Given that there are over 4,500 teaching personnel in each of these fields teaching an undergraduate population of 80,288 mechanical and 75,302 electrical engineering students, it would seem likely that a higher proportion of the teaching personnel are females ${ }^{20}$. To visualize the stark contrast with other fields in engineering, Figure 1 shows the faculty member numbers in each field of engineering broken down by gender, and Figure 2 shows the percentage of female faculty members in each field.

These figures show that only three fields have a lower percentage of female faculty members, and two of these fields are specialized sub-fields of mechanical engineering-aerospace and nuclear. This clearly shows that the problem of extremely low numbers of female faculty members is most prevalent in the field of mechanical engineering.

Figure 1: Number of Engineering Faculty Members by Discipline and Gender

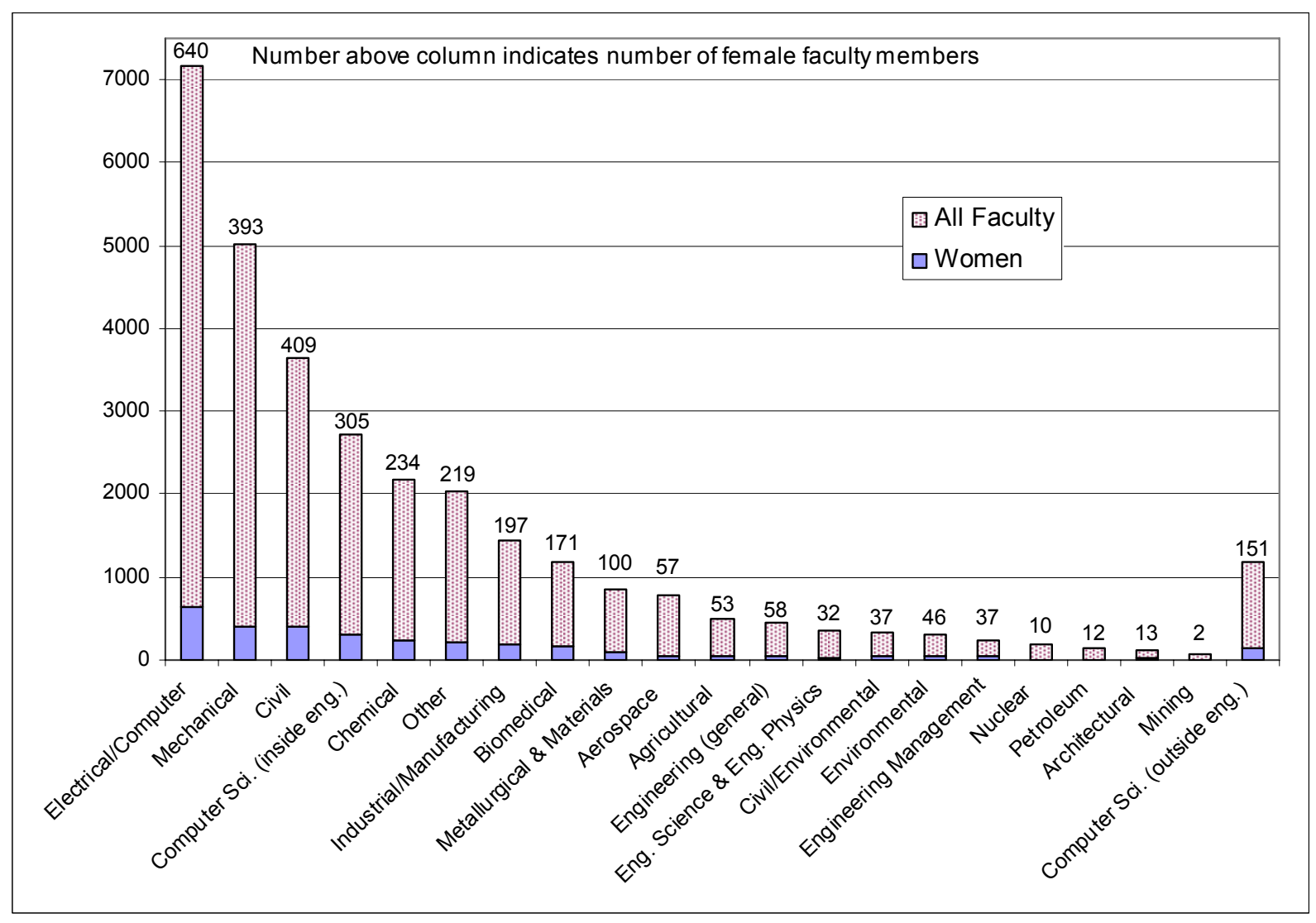


Figure 2: Percentage of Female Engineering Faculty Members by Discipline

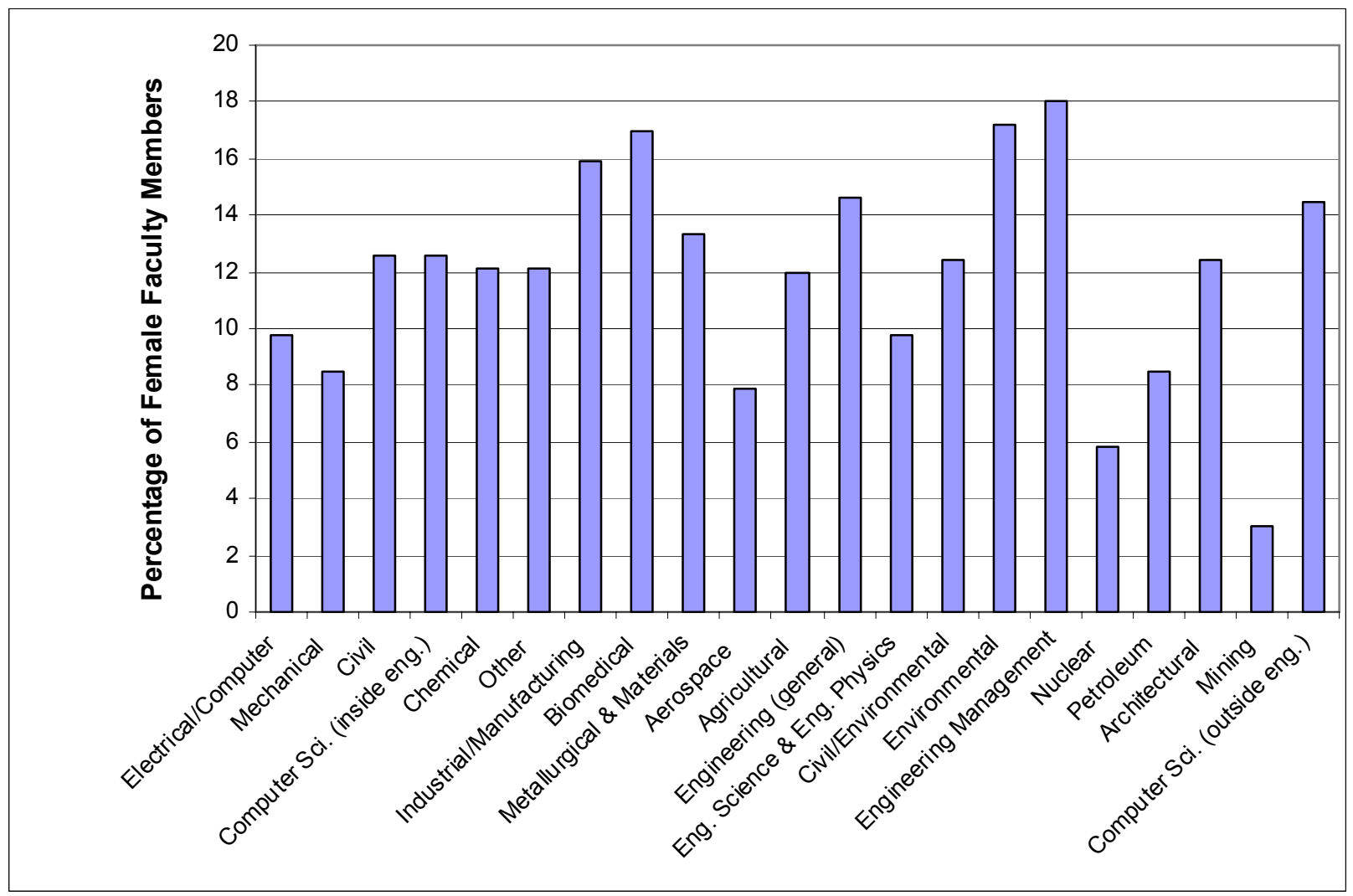

Unfortunately, data from the National Science Board in its Science and Engineering Indicators 2006 report shows that the pipeline into the professoriate does not show significant increases in women completing doctoral degrees in mechanical engineering, resulting in a limited number of candidates available for faculty positions ${ }^{2}$.

\section{$\underline{\text { Research Goals and Questions }}$}

The primary goal of this research study was to investigate the factors that support or impede women's interest and persistence in the field of mechanical engineering and how these experiences influence their decision to complete a doctoral program and advance on to a career in academia. The researchers' specific aim was to develop an understanding of the experiences of women engineers in the professoriate. There are significant gender gaps concerning entry into the field of engineering which become even more pronounced among engineering faculty members at colleges and universities across the country. This study examined key variables along the STEM continuum that contribute to this gender gap through comparative case studies of female engineering professors from eight universities across the United States.

A secondary goal of this study was to compare the perceptions of male and female engineering professors concerning the departmental and institutional climate within their respective university engineering programs and its combined influence on female engineering professors. The intent was to determine the commonalities and differences that exist within and between these two groups to gain additional insight into the problem of underrepresentation of women in STEM fields. 
The researchers explored the following broad research questions:

1. "What are the educational, societal, and institutional barriers and facilitators that influence women to pursue a doctoral degree in engineering and a subsequent faculty position?"

\section{2. "How do male and female professors compare regarding their perceptions of the influence of the departmental and institutional culture on the career development of women engineering faculty members?"}

Under the rubric of the first question, there are a variety of sub-questions, addressing potential contributing factors that range from family influence, K-12 education, undergraduate and graduate education, mentoring experiences and the culture within engineering departments. The goal of such questions was to discover and describe how the female participants' experiences and interactions in informal and formal educational settings inhibited or encouraged her interest and performance in science and engineering. Along these same lines, the male engineering professors were asked to describe their views on the institutional and departmental climate in academia and how these factors affect women's career development and success.

These questions enabled the researchers to discover and describe how these variables affect interest, performance, and choice of science and engineering as viable careers for women. The researchers also, in turn, asked about the present relationships these engineering faculty members have fostered with their own engineering students, whether they view this as an important responsibility associated with their position as a faculty member, and what changes they believe are necessary to achieve a more equitable and inviting educational environment for women in engineering. Particular emphasis was placed on identifying significant differences among the male and female subjects.

\section{Contribution to Knowledge Base}

Research has shown the differences in academic population by gender. In a study done by the Committee on Women in Science and Engineering of the National Research Council, researchers determined that although women professors are found more often in research universities now than in 1973, the number of women in the engineering workforce at Research I universities is only 6 percent ${ }^{13}$. Long's ${ }^{13}$ study addresses the differences in the careers of male and female scientists and engineers, but did not examine the specific factors that may have hindered or supported those females in their efforts to obtain a doctoral degree. The literature on the challenges women face while employed in academia is also rich. A number of studies address the careers of female faculty members, and many focus on the role of career satisfaction on retention ${ }^{15,16}$. These two studies are wide reaching in that the participants are faculty members in all fields, but only one research site is used in each study. The current research base has not affected policy changes that allowed for a significant increase in the number of women entering mechanical engineering who ultimately become faculty members, so more research must be published to achieve this goal. In another key study, the National Science Foundation determined that a major difference between men and women science and engineering majors is the lack of female faculty members as role models ${ }^{14}$. Chesler and Chesler ${ }^{17}$ offer "mentoring as a solution", where they believe that if female faculty members are successfully mentored, a more congenial and cooperative community will develop in academia. If this type of community is developed within an engineering department, it could positively affect everyone in the department from administrators to students, thereby promoting a more supportive and encouraging atmosphere for young women to learn and thrive. 


\section{Methodology}

The design of the study involves a comparative, multi-case study approach. In this approach, multiple cases are examined, and then compared and contrasted to illustrate the issues ${ }^{18,19}$. Data were collected using a set of twelve open-ended interview questions developed by the researchers to address the sub-questions contained within each of the broad research questions (see Appendix A). The participants for the study were located using the American Society of Engineering Education (ASEE) Profiles of Engineering and Engineering Technology Colleges ${ }^{20}$ which has an index of engineering institutions and the degree programs offered. Using this index, the researchers developed a list of all institutions that grant degrees in mechanical engineering, and then further investigated the mechanical engineering departments at the institutions. Institutions were eliminated from the study if the number of female faculty members was less than two. The institutions included in the current study were those that fit these requirements and were easily accessible for the researchers. A number of mechanical engineering faculty members at each institution were initially contacted by email to request their participation in the study, some responded immediately with acceptance or refusal, others were contacted by phone. When at least two male and female faculty members agreed to participate, the researchers did not continue to contact other faculty members.

The sample included thirty-two faculty members in engineering from eight universities across the United States as shown in Table 1 below.

Table 1: Geographic Location of Universities

\begin{tabular}{|l|c|c|}
\hline & \# of Universities & \# of Faculty Members \\
\hline Northeast & 3 & 12 \\
\hline Southeast & 2 & 8 \\
\hline Midwest & 3 & 12 \\
\hline TOTAL & $\mathbf{8}$ & $\mathbf{3 2}$ \\
\hline
\end{tabular}

The purposeful sample of a minimum of two male and two female professors from each university was selected to include a diverse group, specifically including a representation of professors from different ethnic backgrounds and faculty ranks, and from universities that are both public and private (See Tables 2 and 3 ). The sample also included professors from a variety of academic backgrounds and mechanical engineering disciplines. The thirty-two subjects were interviewed in depth to gather information necessary related to the research question. This approach allowed the researchers to gain information about key factors related to the research questions from all individuals.

Table 2: Participant Distribution by Rank

\begin{tabular}{|l|c|c|c|}
\hline & Female & Male & TOTAL \\
\hline Non-Tenure Track & 2 & 0 & 2 \\
\hline Assistant & 8 & 8 & 16 \\
\hline Associate & 3 & 6 & 9 \\
\hline Full & 2 & 3 & 5 \\
\hline TOTAL & $\mathbf{1 5}$ & $\mathbf{1 7}$ & $\mathbf{3 2}$ \\
\hline
\end{tabular}

Table 3: Participant Distribution by Nationality

\begin{tabular}{|l|c|c|c|}
\hline & Female & Male & TOTAL \\
\hline United States & 9 & 12 & 21 \\
\hline International & 6 & 5 & 11 \\
\hline
\end{tabular}


The researchers scheduled interviews with the participants in their respective offices on their respective campuses. The researchers briefly summarized the intent of the research and then began by asking the participants what led them to enter the field of mechanical engineering. This question helped the participants to naturally progress through their K-12 educational experiences, family experiences and into their undergraduate education. Continuing through the educational career, the participants were asked to discuss their experiences with mentoring throughout their college education. Participants were then asked to discuss their life as a faculty member. Specific questions asked about mentoring, climate for collaborations, interactions with colleagues, experiences with tenure and promotion, and experiences with teaching and students. Finally, participants were asked a number of questions about the reasons for the underrepresentation of women in the field of mechanical engineering, and the extent to which society plays a role in this situation. The interviews were varied in length, but most typically lasted about fifty minutes.

In terms of analysis, the researchers began by grouping the major concepts addressed in the research questions according to general categories (mentoring, tenure \& promotion, collaborations, underrepresentation). After coding the data, themes were developed within these categories by way of the constant comparative method method ${ }^{21}$, which is typically used in multi-site studies. The themes were then developed into propositional statements that serve to best represent the collective story of the cases ${ }^{19,21}$. Participant responses that are representative of the propositions are provided to illustrate the concepts in greater depth.

\section{Findings}

The themes that emerged from the interview data fall into four major categories: equitable mentoring; challenges associated with tenure and promotion; climate related to faculty collaborations within mechanical engineering departments; and, factors contributing to the underrepresentation of women in mechanical engineering. Within these four categories, there were a number of ideas that were repeated in multiple interviews. Under the topic of equitable mentoring, the recurring themes included: the stark difference between undergraduate and graduate mentoring; the potential impact of a mentor of the opposite sex; and, the high variability of quality of mentoring received as a new faculty member. As far as tenure and promotion are concerned, the areas most frequently discussed include: the process of tenure and promotion; the potential double stigma for female faculty member hires; and, the issues associated with extension of the tenure clock. Common themes related to collaborative climate in the department of mechanical engineering were: issues related to grant and publication collaboration; rewards associated with being a strong female faculty member; and, the need for a critical mass of female faculty members. Finally, a few items were constantly repeated as factors that contribute to the underrepresentation of women in mechanical engineering, specifically: the lack of role models and information about mechanical engineering and the negative social perceptions and stereotypes associated with mechanical engineering. All of these issues will be discussed in more detail in the following sections.

\section{On equitable mentoring}

\section{$\underline{\text { Lack of undergraduate mentors }}$}

The majority of faculty members of both genders agreed that they received no mentoring from their undergraduate professors. This suggests a significant missed opportunity to encourage and support potential future engineering faculty members who show promise. Those faculty members who received mentoring as an undergraduate had atypical opportunities to interact with undergraduate professors as work-study students or on independent study projects; they 
considered these interactions to be key factors in their decision to enter graduate school. One female faculty member said:

I didn't even really understand anything about grad school when I got here, and then after a couple of years people were encouraging me to think about grad school. I'm sure the research experience was why I continued to go to grad school.

A male faculty member indicated similar positive mentoring based on his undergraduate research experience when he described his mentor's suggestion to understand his own unique strengths and position himself to capitalize on these unique strengths.

\section{$\underline{\text { Positive mentoring from doctoral/thesis advisor }}$}

Encouragement from doctoral or thesis advisors was cited by a majority of faculty members as being a significant factor in their decision to pursue a doctoral degree. Male faculty members tended to attribute this to the fact that, by default, an advisor becomes a mentor due to the nature of the relationship, though the depth of this relationship is often dependent on the personality of the advisor. Female faculty members were more likely to point out the need for extra encouragement from advisors to consider and actually pursue faculty positions in engineering. One female faculty member recalled:

I thought I was just going to get a masters degree, get a job, and be done with my graduate education... he [advisor] is the one who really encouraged me to get a PhD. I had no idea what a PhD was before.

Other female faculty members realized that the critical time for their mentoring occurred during their doctoral degree work. This was when the women typically decided whether to pursue a career in academia. This was most evident as female faculty members reported the need for mentoring about how women can be mothers, wives, and productive faculty members. The importance of this type of mentoring for females considering a career in engineering academia is illustrated by the comments made by two female participants:

There needs to be mentoring and coaching needs to be started at an early level, and how you have a career, in this discipline, and still have your life at the same time.

We need to communicate that yeah, it's a challenging job but there are people who are happy, and I'm one of them, having done both. I'm fully satisfied, and I cannot imagine having done either one independently...tell them, yeah it's tough, I'm not going to lie to you, it's going to be tough, you are going to go through tough years, but first of all it's a limited number of years compared to your whole life.

\section{Effect of sex of faculty advisors}

Some male faculty members perceived that male faculty advisors often interacted with their female graduate students differently than their male graduate students. A number of male faculty members described experiences they had when they were in graduate school to illustrate this:

The few female graduate students around were exclusively Asian, and they were much more non-questioning of their advisors and were more easily pushed around.

On the contrary, female faculty members did not report any differences in interactions:

There was my advisor who was very fair to all his students, but he did not mentor me because I was a woman more than his other students. 
Variable mentoring as a new faculty member

Many engineering faculty members reported that there was no official mentoring program within their department. The few respondents that did report having an assigned mentor indicated varying degrees of satisfaction with their mentor. In all cases, the reported satisfaction was directly related to the degree of the assigned mentors' desire to be a mentor. Female engineering faculty members described a number of opportunities to meet with other female faculty members at social events, though this tended to be at university-wide or college-wide events, since there were not many women in the engineering department. For instance, Women in Science and Engineering (WISE), Women in Engineering Leadership (WIEL), and NSF-sponsored Project Advance events were mentioned by a number of female faculty members as being excellent opportunities to get positive mentoring advice from colleagues.

At the same institutions, several male faculty members suggested that they didn't feel as though they had as many opportunities for mentorship as their female colleagues because they couldn't participate in these special programs designed for female faculty. The female faculty members noted were sometimes reluctant to ask male colleagues for help or to have lunch with them for fear of being perceived as needy or weak. One female faculty member mentioned her concern about what others might perceive of her relationship with her male colleagues:

I cannot comfortably go out and have lunch with my [male] colleagues because I'm a female. And if you go out with people on a one-on-one lunch to talk about something, then people start to look at you differently, and they think, what's going on between these male and female faculty members?

Several male faculty members pointed out that they wondered if female faculty members perceived their mentoring to be less effective or accessible because they were consulting mostly with male colleagues. They suggested that as more women are hired in the department there may be less of a feeling of isolation, perhaps making it easier for the women to find positive mentoring support. One female faculty member recounted her experiences as a new faculty member stating:

I was the only woman in my department, so I was promoted, and then I went to a place where there was a woman, but she didn't get tenure. And so all along I have been the only woman in my [engineering] department.

\section{Challenges associated with tenure and promotion}

\section{$\underline{\text { Seemingly similar process for all faculty members }}$}

Most engineering faculty members interviewed thought that the expectations for tenure and promotion at their university were clear, or as clear for them as anyone else, and that they knew what they had to do professionally to achieve tenure. A number of senior faculty members reported serving on the tenure and promotion committee and seeing no differences in the treatment of male and female faculty members within engineering departments. One female faculty member, however, felt differently:

I still feel like you're scrutinized a little bit more as a woman. Just making sure that the ideas are yours, as a female, and not from your male collaborators.

Several male faculty members commented that women faculty members might have in fact, an easier time securing grants because of special NSF funding sources and initiatives targeted at females, but none of the women faculty members mentioned this point. 


\section{$\underline{\text { Double stigma for women faculty members }}$}

The majority of female faculty members described feeling a double stigma of possibly being hired because they are a female and then having to work extra hard to prove they are both deserving of the position and earned the job because of their qualifications. The following quotes from female engineering faculty members reflect the nature of this stigma:

Everywhere I go, I have to put in extra effort to first prove myself; even with the students, they have more respect for a male teacher than a female teacher.

There are people out there who are extremely supportive of diversity, and are going to help, but there are also people out there who are prejudiced, and don't think that underrepresented minorities can do it.

In addition to the implicit assumption that often comes with being a female in engineering, that you were hired just because you were a female, in my case I found out essentially that was true; the department was given a position only if they filled it with a female or a minority. I don't think I was supposed to know that, but I found that out.

One female faculty member felt strongly that when engineering departments are empowered to create engineering faculty positions for exceptional female applicants, this positively benefits women:

We don't have a position open, but if you can find a good female faculty we will make it happen. It's much easier for the Dean to go to the Provost and say I have a great female [engineering] faculty candidate compared to having a male faculty...I think it gives us a lot of competitive advantages.

Other female faculty members discussed institutions that have procedures to support new minority faculty hires through special university funding lines, not departmental funding lines. A senior male faculty member agreed that there could be negative perceptions about why a female was hired when he discussed his thoughts on the departmental climate:

I have a suspicion that there are some people who say-she got the job because she's a woman... [this was] not explicitly said to me, but there is a body language.

\section{Extending the tenure clock}

The male faculty members were able to articulate their thoughts on the difficulties of being a woman in academia, although this topic rarely emerged without probing questions from the researchers. One male faculty member, who had served regularly on the tenure and promotion committee, explained:

It's very challenging to be able to raise a family, take care of your kids, and have a fulltime job... You can ask for maternity leave; you may or may not get it. You can ask for your tenure year later; you may or may not get that extension. So these are all examples of the additional challenges that [women] face.

Similarly, male faculty members did not consistently report whether extending the tenure clock for childbirth or other family issues were a possibility at their institution. There was largely a lack of knowledge about options for extension of the tenure clock unless the male faculty member had worked on the tenure and promotion committee or had experience with colleagues who had extended their tenure clock. 
A number of female faculty members expressed disappointment with male colleagues' attitudes about childbirth and the effect it has on the female faculty members:

When I was in the hospital for an extended period after giving birth, nobody thought it was appropriate to send me a note to say we're thinking about you...because it's related to childbirth, and that part of the body that is not supposed to be exposed.

There are some male faculty members who are not very open-minded and they think that when the female faculty members have kids they will never come back to teach again.

The female faculty members did not necessarily take advantage of the option to extend their tenure clock after the birth of a child. In fact, a number of senior women faculty members had children before they were awarded tenure and did not take extra time; some even went up for tenure consideration early.

\section{Climate related to collaborations within mechanical engineering departments}

\section{$\underline{\text { Collaborations on grants and publications }}$}

Senior female engineering faculty members recalled that prior to earning tenure, they were often advised to do their research alone and only publish with their graduate students as co-authors to avoid the appearance that they may be unable to do their job independently.

When I came here, one piece of advice I was given was be careful how much you collaborate, because when you go up for tenure, if you and big shot professor $X$ have a joint proposal and joint papers, the assumption is it's all big shot professor X's ideas.

These female respondents however, realize that the research environment has changed dramatically in recent years, and now it would be impossible for an engineering faculty member to do all of his or her research alone because the funding agencies provide money in large chunks and collaboration is essential.

With regard to collaboration, the female faculty members reported that creating a collaborative network is harder for them because as colleagues put research teams together, they tend to look for people like them to work with.

Men with men are natural. If they have lunch or dinner together, they start to chat and then they write proposals together.

[As a woman], you might not be the first person on the list [of potential collaborators] because the men will think of other people like them. White males are sitting there saying, I have to build this team, well I'll get other white males on the team. It's part of our nature.

Because of this tendency, the female faculty members felt forced to be the first ones to reach out to their male colleagues for collaboration on projects. Many of the junior female faculty members chose their current university because of its reputation for interdisciplinary work and collaboration among departments. They note that it was difficult to begin to forge relationships with male colleagues, once they began their collaborations the interactions tended to be very positive:

I couldn't have done what I've done without the access to other faculty's facilities at the university...In most cases they are so generous to let me use the equipment. 
The nature of my research is interdisciplinary, and I now have a number of collaborations with male and female faculty members in different departments on campus.

$\underline{\text { Reward for being a strong female faculty member within the engineering department }}$

Female faculty members reported that as they become more respected within their departments and in their field they are given additional responsibilities and opportunities such as being asked to serve on more committees and panels. The faculty members noted that this could be positive because it is good for the service portion of tenure, but also negative because more commitments can take away from the time necessary to conduct good research. One female faculty member stated:

As the lone female you're more visible, and that's a good thing, because it can help with getting these leadership opportunities.

Need for a critical mass of female engineering colleagues

A number of male faculty members noted that they felt the lack of a connection that some female faculty members in engineering might feel can be overcome when a critical mass of female faculty members exists allowing them to create their own support network. A senior female faculty member recalled how the department changed as more women faculty members were hired:

It's enormously different from being the only woman in a faculty meeting...I have seen the change become a critical mass... the whole atmosphere is different. There is a whole bunch of senior women you can go to for advice. It makes it easier to be more successful and you are accepted more immediately.

A junior female faculty member reflected on having two senior women colleagues when she joined her institution and how it made her (and other junior females in the department) feel more comfortable because male colleagues have experience dealing with women faculty members. She summarized by saying:

When you see a model, a very successful model, then you see your future. When a male comes in and they see many models, then they know that they can become successful.

\section{Factors contributing to the underrepresentation of women in mechanical engineering}

$\underline{\text { Lack of role models and information about mechanical engineering }}$

Many female faculty members discussed the life-work balance, and how hectic this can be for those in academia. A number of them wondered whether they were good models for their own graduate students, or whether they were just examples of how difficult it is to be a female professor. The women stressed the importance of having support structures at home to help with childcare and managing the household. They recalled other female $\mathrm{PhD}$ graduate student colleagues who had not considered an academic career because of the perceived difficulties associated with the tenure process and the fact that this falls within the timeframe of marriage and childbirth. One male faculty member described similar attitudes:

Child-rearing probably keeps a lot of women out of jobs like science and engineering faculty. 
All faculty members said that students need to see examples of successful male and female engineers before they will choose engineering as a career path. Similarly, all faculty members thought that students in K-12 need more information about and exposure to career options in mechanical engineering. Faculty members thought that many students don't know what mechanical engineering is all about. This may lead to assumptions that it's all about cars, airplanes and machines which many faculty members felt would not be traditionally appealing topics for females. A small number of faculty members raised the issue that many female students enter biology, biomedical engineering or civil engineering because they see the applications of these fields and that appeals to their desire to help others or society as a whole.

\section{Negative social perceptions/stereotypes}

Faculty members repeatedly said during the interviews that young females learn at an early age that certain behaviors/traits/toys are geared for boys or girls by parents, media, books, etc. and many children hold on to these incorrect stereotypes. Many faculty members discussed experiences that they had as a child, or with their own children where they sensed negative influences outside of the home. Two male faculty members relayed:

My daughter [ $2^{\text {nd }}$ grader] said to me, usually boys do better in math. She is in advance math and she sees that there are only two or three girls... so she thinks that she's a little different. It doesn't stop her from trying math, but she's beginning to think she's a little different from regular girls.

There is a strong bias against women doing well in the hard sciences...From a very early age I think they feel themselves that's not a direction they should go and feel discriminated against. I think it starts very early, 8-9 years old, they know there is something different about that field of pursuit.

Many of the respondents described the perception that mechanical engineering is boring and it seems out of date and useless. One female faculty member expressed this directly when she stated:

It's not a sexy field...it's not portrayed in the media as being glamorous or having societal impacts such as medicine or environmental studies.

Female faculty members went on to explain that this perception leads to the elimination of a large number of students who don't see the relevance of the field, and don't believe that engineers are people who can be fashionable, well-spoken, and worldly. Two senior women faculty members described what the engineering community should communicate to young women about engineering:

You're left with people who are happy to be nerdy. Mechanical engineering doesn't have that mystique to it. Little girls need to be told that it's cool to be nerdy.

I think the more balanced engineers are, the better they are and the better prepared they will be to advance issues which nowadays are interdisciplinary issues, which not only cross the boundaries between engineering fields but also between engineering and the arts, engineering and the humanities... We need to get the word out there that it's okay to dress fashionably and wear makeup and speak in a loud voice, and be an engineer as well. 


\section{Conclusions and Future Work}

The outcomes of this study shed light on some of the issues that may specifically relate to women in mechanical engineering, such as the need for a critical mass of women faculty members, the effects of a negative departmental climate, and the need for accurate communication about the field of mechanical engineering, itself.

It is interesting to note the almost universal lack of mentoring at the undergraduate level that these respondents experienced. This is the point in a student's career when they experience academia for the first time, and it makes sense that professors should encourage bright students to continue on for graduate degrees. A strong implication from this information would be for mechanical engineering faculty members to spend additional time mentoring undergraduate students and providing them with opportunities for independent research projects. Monhardt, Tillotson, and Veronesi ${ }^{22}$ similarly found that undergraduate education was the time when students most often decide whether or not to pursue a career in science.

An interesting point concerning mentoring at the graduate level is the increased need for faculty members to encourage their female doctoral students to consider a career in academia. Doctoral students need to understand the typical tenure process and length of time involved, and they need to see examples of female faculty members who are getting the support they need at their institution. Without these examples, doctoral students will likely continue to believe that it is impossible to be a faculty member, wife, and mother. A number of other studies have found that women choose not to pursue a career in academia because of issues related to mobility, parenting, and an undesirable work environment ${ }^{13,23}$.

With regard to faculty mentoring programs, it seems that the success of these programs lies with the mentors themselves. If the assigned mentor has no interest in mentoring a junior faculty member, the interaction tends to be of little value for the junior faculty member. Unofficial mentoring, where junior faculty members reach out to individuals with similar research interests seems to be as successful as, or perhaps even more successful than having an assigned mentor. The same holds true for institutional-wide programs such as WISE or Project ADVANCE events, where some female faculty members participate regularly and others just don't have the time.

Overall, the tenure and promotion process seems to be equivalent for male and female mechanical engineering faculty members. One of the issues, however, centers on whether a female is hired to "fill a slot" or because she is a capable engineering researcher. A number of faculty members reported that sometimes females and minorities are hired at their institutions because they have a faculty line open exclusively for a minority candidate in the field. Though on the surface this seems to be a positive way to increase the proportion of women and minority faculty members in a department, there tends to be a negative connotation associated with the hiring. Sonnert ${ }^{6}$ found a number of obstacles towards women in the hiring, promotion, and tenure realms, and attributed them to department chairs, tenure committees, and colleagues who are biased towards women. It seems that in the past decade a lack of hiring, promoting, and granting tenure to female faculty members has evolved to a stage where institutions actively seek out women. Another issue for female mechanical engineering faculty members has to do with the option to extend the tenure clock following the birth of a child. At some institutions this is highly encouraged for new parents, and at others there is stigma associated with taking the tenure clock extension option. This implies that institutions need to make an effort to publicize tenure extension policies and encourage new parents to take advantage of the policies.

The reported climate for collaboration as a new faculty member is initially cool for female faculty members. Once they begin developing relationships with colleagues, however, it becomes more positive. Other studies have found that women faculty members in the hard 
sciences have lower quality departmental relationships and a lower number of interdepartmental relationships ${ }^{7}$. Many faculty members realize the importance of having a critical mass of female faculty members and the positive atmosphere it can create for female faculty members and students in engineering. In agreement with this, Trower and Chait ${ }^{24}$ found that the percentage of female faculty members at a college is the most accurate predictor of success for female students.

Faculty members tended to describe similar reasons for the underrepresentation of women in mechanical engineering, not unlike those discussed in other research reports ${ }^{5,25,26}$. Role models are necessary at all stages of the academic career, and accurate information must be given to students, parents, teachers, and guidance counselors about what mechanical engineering is, what mechanical engineers do, and how mechanical engineers can make a difference in the world. In conjunction with this, faculty members believe the negative social stereotypes that describe engineering as boring, and engineers as nerdy and unfashionable, need to be overhauled.

The findings reported here contribute to the knowledge base on mechanical engineering faculty members' experiences with mentoring, tenure, and perceptions of the institutional and departmental climate within engineering programs across selected regions of the United States. While the study was limited by the small number of universities selected and the small number of faculty member participants from each site, future research plans include sampling participants at universities in the northwest and south.

\section{Bibliography}

1. National Science Foundation, Broadening participation in science and engineering faculty. Arlington, VA. (NSB-04-41) 2004.

2. National Science Board, Science and engineering indicators 2006. Two volumes. Arlington, VA: National Science Foundation. (volume 1, NSB 06-01; volume 2 NSB 06-01A) 2006.

3. J.S. Mcllwee and J.G. Robinson, Women in Engineering: Gender, Power, and Workplace Culture. Albany, NY: State University of New York Press 1992.

4. G. Sonnert and G. Holton, Who Succeeds in Science?: The Gender Dimension. New Brunswick, NJ: Rutgers University Press 1995.

5. H. Etkowitz, C. Kemelgor, and B. Uzzi, Athena unbound: The advancement of women in science and technology. Cambridge, United Kingdom: Cambridge University Press 2000.

6. V. Gornick, Women in science: portraits from a world in transition. New York, NY: Simon and Schuster 1983.

7. J. Plummer Cobb, "Planning Strategies for Women in Scientific Professions," In V.B. Haas \& C.C. Perrucci (Eds.), Women in Scientific and Engineering (pp. 75-88). Ann Arbor, MI: The University of Michigan Press 1984.

8. E. Saraga and D. Griffiths, "Biological inevitabilities or political choices? The future for girls in science," In A. Kelly (Ed.) The missing half: Girls and science education (pp 85-97). Manchester, England: Manchester University Press 1981.

9. S.G. Brainard and L. Carlin, "A six-year longitudinal study of undergraduate women in engineering and science," in M. Lederman and I. Bartsch (Eds.), The Gender and Science Reader, London, England: Manchester University Press 2001.

10. R. Carter and G. Kirkup, Women in engineering: A good place to be?, Basingstoke, England: Macmillan 1990. 
11. D.J. Nelson, "A national analysis of diversity in science and engineering faculties at research universities," Retrieved August 1, 2007, from Department of Chemistry University of Oklahoma, Website: http://cheminfo.ou.edu/ djn/diversity/briefings/Diversity\%20Report\%20Final.pdf 2005.

12. M. Wyer, "Intending to stay: Images of scientists, attitudes toward women, and gender as influences on persistence among science and engineering majors," Journal of Women and Minorities in Science and Engineering, 9, 1-16 2003.

13. J.S. Long (Ed.), From scarcity to visibility: Gender differences in the careers of doctoral scientists and engineers. Washington, DC: National Academy Press 2001.

14. National Science Foundation, Broadening participation in science and engineering faculty. Arlington, VA. (NSB-04-41) 2004.

15. L. August and J. Waltman, "Culture, climate, and contribution: Career satisfaction among female faculty," Research in Higher Education, 45:2, 177-192, 2004.

16. P. Bronstein and L. Farnsworth, "Gender differences in faculty experiences of interpersonal climate and processes for advancement," Research in Higher Education, 39:5, 557-585, 1998.

17. N.C. Chesler and M.A. Chesler, "Gender-informed mentoring strategies for women engineering scholars: On establishing a caring community” Journal of Engineering Education, 91:1, 49-55, 2002.

18. R.C. Bogdan and S.K. Biklen, Qualitative research for education: An introduction to theory and methods, Boston, MA: Pearson Education Group 2003.

19. J.W. Creswell, Qualitative inquiry and research design: Choosing among five approaches, Thousand Oaks, CA: Sage Publications 2007.

20. American Society of Engineering Education, Profiles of Engineering \& Engineering Technology Colleges 2004 Edition. Washington, DC 2005.

21. A. Strauss and J. Corbin, Basics of qualitative research: Grounded theory procedures and techniques, Newbury Park, CA: Sage Publications 1990.

22. R.M. Monhardt, J.W. Tillotson, and P.D. Veronesi, "Same destination, different journeys: a comparison of male and female views on becoming and being a scientist," International Journal of Science Education, 21:5, 533-51, 1999.

23. S.M. van Anders, "Why the academic pipeline leaks: Fewer men than women perceive barriers to becoming professors," Sex Roles, 51(9/10), 511-21, 2004.

24. C.A. Trower and R.P. Chait, "Forum: Faculty Diversity," Harvard Magazine, 104(4), 33-7, 2002.

25. R. Asera and U. Treisman, "Routes to mathematics for African-American, Latino, and Native American students in the 1990s: The educational trajectories of summer mathematics institute participants," CBMS Issues in Mathematics Education, 5, 127-51, 1995.

26. P. Chacon and H. Soto-Johnson, "Encouraging young women to stay in the mathematics pipeline: Mathematics camps for young women," School Science and Mathematics, 103(6), 274-84, 2003. 